\title{
INTENTOS MODERNIZADORES EN EL DERECHO SOCIETARIO CHILENO: ANÁLISIS DE LAS LEYES 20.494 Y 20.659*
}

\author{
María Fernanda VÁsQuez Palma**
}

RESUMEN: La modernización del Derecho societario ha tendido -entre otras múltiples aristas- a la simplificación de ciertos trámites tradicionales de su constitución, modificación y solución, de la mano del análisis económico del derecho, la electronificación del derecho en general, y la internacionalización de los mercados. Chile, en su intento por estar mejor posicionado en los rankings internacionales, también ha efectuado algunas modificaciones en esta materia. La presente investigación tiene por objeto estudiar y analizar los cambios legislativos instaurados, en aras de analizar sus aspectos más relevantes y algunas posibles problemáticas.

PALABRAS CLAVE: Simplificación Derecho Societario - Leyes Chile

\section{MODERNIZING ATTEMPTS IN CHILEAN COMPANY LAW: ANALYSIS OF LAWS 20.494 AND 20.659}

\begin{abstract}
The modernization of company law has tended, -among other multiple edges- a simplification of certain traditional formalities in its constitution, modification and solution, with the help of economic analysis of law, the overall electronic innovations in the field of law, and the internationalization of markets. Chile, in an attempt to be better positioned in the international rankings, has also made some changes in this area. This research aims to study and analyze the legislative changes, in order to analyze ones its most relevant and some introduction of these possible problems.
\end{abstract}

KEY WORDS: Corporate Law Simplification - Laws Chile

\footnotetext{
* Este texto forma parte de un Proyecto de Investigación Fondecyt Regular N ${ }^{\circ}$ 1130376, denominado "La modernización del Derecho societario en Chile: Un análisis sincrónico a partir de las políticas legislativas adoptadas en Derecho comparado", del que la autora es investigadora responsable.

Fecha de recepción: 15 de noviembre de 2013

Fecha de aceptación: 27 de marzo de 2014

** Profesora Asociada de Derecho privado. Facultad de Ciencias Jurídicas y Sociales, Universidad de Talca. Doctora en Derecho por la Universidad Complutense de Madrid. Correo electrónico:mfvasquez@utalca.cl
} 
Sumario: Introducción. 1) Revisión de las iniciativas legales junto a sus fundamentos. (1.1.) Ley 20.494. (1.2.) Ley 20.659. 2) Análisis de los cambios legislativos. (2.1.) Principales aspectos de la ley 20.494. (2.2.) Principales modificaciones realizadas por la ley 20.659. 3) Evaluación de las leyes en su aplicación práctica. (3.1.) Aumento en la constitución de sociedades. 4) Algunos cuestionamientos necesarios. Conclusiones

\section{INTRODUCCIÓN}

El fenómeno legislativo de la modernización del Derecho societario ha tendido de una manera prácticamente unívoca a la simplificación o flexibilización del mismo, no sin antes enfrentar múltiples vicisitudes y controversias. En ello han incidido una sumatoria de factores económicos, jurídicos y tecnológicos ${ }^{1}$, cuyo análisis, es vital para lograr una visión completa del fenómeno que aquí subyace ${ }^{2}$.

Este proceso obedece, en primer lugar, a la necesidad de adaptar el marco jurídico de las empresas a la progresiva internacionalización y globalización de los mercados, así como al crecimiento económico de un determinado país. Frente a ello, hemos de considerar que la formación de una sociedad no es fácil, en tanto tiene asociados diferentes costos de instalación y funcionamiento que dependen de la legislación aplicable (lex societatis) y que se vislumbran no solo en la materialidad misma de su constitución, sino también en los plazos y trabas administrativas derivadas de la normativa que rige a la sociedad en cuestión ${ }^{3}$. A ello debemos agregar costos derivados de la organización interna, funcionamiento de los órganos sociales, adopción de normas de organización, del estatuto del socio, de disolución de la sociedad, fusión, división, transformación, entre otras. Estos costos pueden, en muchos casos, obstaculizar la creación o el adecuado funcionamiento de una sociedad, constituyéndose en verdaderas barreras de crecimiento.

En base a lo anterior, las nuevas tendencias, de la mano del análisis económico del Derecho, se han inclinado por la disminución de los costos principalmente al comienzo de la actividad, pues esta es la fase de mayor

1 Hierro Anibarro, Santiago, (2010), "Una introducción a la simplificación del Derecho de sociedades”, en Hierro Anibarro, Santiago (Director), Simplificar el Derecho de Sociedades, Madrid, Marcial Pons, p. 17.

2 Lamentablemente los trabajos que presentan un enfoque multidisciplinarios no son frecuentes, a diferencia de lo que ocurre en el ámbito norteamericano. Véase: Hopt, K. J. (2007), "Corporate Governance: Vergleichende privatrechtliche Forstchung im Aktien -und Kapitalmarktrecht”, en Gesellschaft, Jahresbericht der Max- Planck, p. 22.

3 García Tabuenca, Antonio; Crespo, José Luis; Sanz Tringuero, María, (2010), "El coste económico en la creación de sociedades", en Hierro Anibarro, Santiago (Director), Simplificar el Derecho de Sociedades, Madrid, Marcial Pons, pp. 25-64. 
incertidumbre. En tal contexto, las condiciones económicas ofrecidas a los emprendedores han pasado a ocupar un lugar preponderante en la regulación del Derecho de sociedades, lo que se debe en gran medida a la instrumentalización de la estructura societaria en la formación de empresas.

Las iniciativas que se han tejido a este respecto son variadas. La Unión Europea, por ejemplo, planteó hace ya varios años una política comunitaria para la $\mathrm{PYME}^{4}$, que estableció el primer comité de simplificación administrativa compuesto por funcionarios encargados de evaluar las repercusiones de las disposiciones legislativas o reglamentarias sobre las empresas. Estos documentos dieron como resultado una declaración sobre la necesidad de reducir las formalidades administrativas -comunitarias y nacionales- que pesan sobre las sociedades con el objeto de crear un entorno favorable tanto para su fundación como en su desarrollo 5 .

Con relación al intercambio de experiencias de simplificación, la Comisión Europea sugirió a los Estados miembros que adopten un órgano nacional para la simplificación administrativa del entorno empresarial, con el objeto de elaborar un inventario de las obligaciones impuestas por las legislaciones nacionales a las empresas, además de evaluar otros costes. A partir de ello, la Comisión, a mediados de 1989, presentó un primer informe al Consejo en el que se recogían las mejores prácticas nacionales de simplificación del entorno empresarial junto a las conclusiones extraídas del estudio comparado de las soluciones nacionales ${ }^{6}$. En este lineamiento, el mayor avance se produce con la Decisión 89/490/CEE del Consejo, relativa a la mejora del entorno empresarial y al fomento y desarrollo de las empresas. Con ella se suprimieron los obstáculos de carácter administrativo, financiero y jurídico que impedían el desarrollo y la creación de empresas, en especial de las PYMES?

4 Esta política comenzó a gestarse en la primera mitad de la década de los años 80, a raíz de la aplicación del Libro Blanco sobre la consecución del Mercado Interior y la concepción de las nuevas políticas comunitarias destinadas a crear, sin perjuicio del principio de subsidiaridad, un entorno favorable para la empresa. Véase: Hierro Anibarro, (2010), pp. 135-136.

5 En los dos primeros informes, de junio de 1987 y febrero de 1988, la Comisión emplea la técnica combinada de estudiar las medidas de simplificación de la legislación comunitaria junto al intercambio de las experiencias nacionales sobre esta materia. Véase informes de la Comisión al Consejo sobre la realización de los objetos del programa de la Comunidad para las pequeñas y medianas empresas, COM (87) 238, de 20 de julio de 1987 y 2 de marzo de 1988.

6 Véase Informe de la Comisión al Consejo. Medidas tomadas por los Estados miembros a favor de las empresas en la comunidad sobre simplificación administrativa, SEC (1989), 726 final, de 19 de junio de 1989.

7 La primera dificultad que se planteó con esta iniciativa fue la exacta delimitación del vocablo "simplificar". Para evitar problemas administrativos, la Comisión decidió que el término abarcaba todas las medidas establecidas en la Recomendación 90/240/CEE del Consejo, de 28 de mayo de 1990, relativa a la aplicación de una política de simplificación administrativa en los Estados miembros, en la que el Consejo pedía a los Estados miembros que por simplificación administrativa se entendiera la modernización de la organización de los servicios 
Una de las conclusiones más llamativas de este proceso de simplificación dice relación con el análisis de costes materiales y temporales de la sociedad mediante una labor de confrontación de sistemas normativos. Se establece que existe una relación directa entre el origen de las normas de un país y el número de trámites necesarios para constituir una nueva empresa, ańadiendo que los países anglosajones tienden a exigir un menor número de requisitos que los de Derecho continental europeo cuya raíz se encuentra en un Código de Comercio. El Consejo de la Unión Europea, haciendo eco de estas conclusiones, solicitó a los Estados miembros que antes de 2007 tomaran algunas medidas para facilitar la creación de empresas. Por este camino se ha trazado una nueva noción de empresa, desligada de criterios tipológicos jurídicos, por lo que se trata de un concepto muy extenso que incluye a entidades muy variadas ${ }^{8}$.

Chile no ha estado al margen de esta evolución. Considerando que los trámites de constitución de una sociedad son diversos, ha puesto en los últimos años un foco de atención legislativo en la simplificación de la constitución societaria. Al respecto, ha publicado dos normas relevantes: La ley 20.494, que agiliza trámites para el inicio de actividades de nuevas empresas (publicada en el D.O. el 27 enero de 2011); y la ley 20.659, que simplifica el régimen de constitución, modificación y disolución de las sociedades comerciales (publicada en el D.O. el 8 febrero de 2013). Ambas han significado un cambio importante para el Derecho societario chileno, toda vez que su objetivo se centra en la celeridad de los trámites que deben realizarse para la constitución, modificación y disolución de sociedades, permitiendo con ello que toda persona pueda iniciar una empresa con menores costos asociados.

El presente artículo tiene por objeto analizar precisamente estas normas en el contexto de la modernización general del Derecho societario, revisando sus principales fundamentos, aspectos relevantes de su fisonomía, así como los posibles focos de conflictos que pueden originar. No existen estudios sobre esta materia, de manera que el presente texto pretende constituir un aporte en su comprensión y posible adecuación.

administrativos, en particular, de los que tuviera contacto con las empresas; la normalización y reducción de los formularios, y las declaraciones, entre otras.

8 La Directiva 2009/49/CE del Parlamento Europeo y del Consejo, de 18 de junio de 2009, por la que se modifican las Directivas 78/660/CEE y 83/349/CEE del Consejo en lo que respecta a determinados requisitos de información a medianas sociedades y a la obligación de confeccionar cuentas consolidadas, es el resultado del procedimiento de simplificación, para eximir a estas empresas de determinadas obligaciones de información. 


\section{1) REVISIÓN DE LAS INICIATIVAS LEGALES JUNTO A SUS FUNDAMENTOS?}

En la creación de estas normativas se han esgrimido fundamentalmente aspectos económicos, en aras de facilitar la creación de nuevas empresas. Para ello se ha considerado que los costos financieros y temporales suelen significar un obstáculo para los nuevos emprendedores, lo que a su vez puede terminar haciendo inviable un negocio por implicar la pérdida de una oportunidad o simplemente fomentar la informalidad empresarial, con las graves consecuencias legales, tributarias y de funcionamiento de los mercados ${ }^{10}$.

Este interés se enlaza con la inserción de Chile en el grupo OCDE y su posición en los ranking internacionales. En esta línea, un factor relevante fue el informe Doing Business Chile del año 2010 del Banco Mundial, que ubicó a Chile en el lugar 69 entre 183 economías en relación con la facilidad para iniciar una nueva empresa, detectando la necesidad de realizar 9 trámites con una demora promedio de 27 días. Este antecedente se consideró grave pues en esta materia el país descendió 14 puestos en relación al año 2009 del mismo ranking, lo que motivó la toma de ciertas medidas radicales para cambiar esta realidad y así incentivar el ejercicio de la libertad de emprender. Obsérvese el siguiente gráfico.

\section{"RANKING DOING BUSINESS 2010"}

\section{Comercio Internacional}

Documentos para exportar $\left(\mathrm{N}^{\circ}\right)$

Tiempo para exportar(días)

Apertura de Negocio

$\mathrm{N}^{\circ}$ de procedimientos

Tiempo (días)

Costo \% de ingreso per cápita

Cierre de negocio

Tiempo(años)

Tasa de Recuperación (\%)

\section{Chile OECD Ratio Chile/OECD}

$\begin{array}{rrr}6 & 4,3 & 1,4 \\ 21 & 10,5 & 2,0 \\ & & \\ 9 & 5,7 & 1,6 \\ 27 & 13 & 2,1 \\ 6,9 & 4,7 & 1,5 \\ & & 2,6 \\ 4,5 & 1,7 & 31 \% \\ 21,3 & 68,6 & \end{array}$

$9 \quad$ Basado en la historia de las leyes 20. 494 y 20.596, disponibles en www.bcn.cl

10 De acuerdo a los datos provistos por el Ministerio de Economía, según la encuesta de Micro-Emprendimiento de este ministerio del año 2011, de los emprendimientos informales, en torno a 190.000 empresas estarían en condiciones de formalizarse, ya que al ser encuestadas esgrimieron razones de costos, dificultad de tramitación y desconocimiento entre los motivos por los cuales no han realizado los trámites ante el SII. Además, se sabe que 120.000 empresas han considerado formalizarse, pero finalmente no lo han hecho y otras 57.000 se encontrarían en trámites de formalización en el SII al momento de ser encuestadas. De tal forma, se tendría que los emprendimientos que potencialmente se podrían formalizar son 367.000 , lo que representa a un $37 \%$ del total de emprendimientos informales. 
Esto se debe fundamentalmente a las formalidades que deben atender las sociedades. En tal sentido, debemos recordar que si bien las sociedades civiles carecen de solemnidades de constitución (con la excepción de las sociedades de responsabilidad limitada/SRL), las comerciales deben satisfacer una serie de requerimientos, que pueden resumirse en los siguientes aspectos ${ }^{11}$ :

- Elección del tipo de sociedad, redacción del borrador de la escritura pública de constitución y su extracto ( 1 y 4 días).

- Otorgamiento de la escritura pública y legalización de su extracto en la Notaría (entre 1 y 4 días).

- Inscripción del extracto de constitución en el Conservador de Bienes Raíces (demora 3 a 4 días).

- En algunos casos, la publicación del extracto de constitución en el Diario Oficial (3 a 10 días, con un plazo de 60 días como máximo).

Adicionalmente, las sociedades deben cumplir con una inscripción para la obtención de un Rol Único Tributario, declaración de inicio de actividades (1 día) y timbraje de documentos tributarios (1 a 15 días); a lo que se añade una solicitud de Patente Municipal que conlleva un plazo que va desde 1 a 15 días según el Municipio de que se trate.

Frente a esta realidad, el legislador tuvo por objeto disminuir tales trámites y costos, brindado dos soluciones legislativas en estos últimos dos años, según veremos en el siguiente apartado.

\section{1.) LEY $20.494^{12}$}

Se inició por Mensaje (133-358) de fecha 1 de junio de 2010. Sus fundamentos residieron en las dificultades existentes para crear nuevas empresas y los efectos que ello conllevaba en el crecimiento económico del país.

El proyecto tuvo por objeto fundamental facilitar y agilizar los trámites de inicio de nuevas empresas, adoptando el Estado un rol facilitador del emprendimiento e implementando una labor fiscalizadora ex post que sancione eventuales infracciones. En este sentido, se pretendía la modificación de las normas relativas al otorgamiento de patentes municipales, a la emisión y timbraje de documentos por parte del Servicio de Impuestos Inter-

\footnotetext{
11 El detalle de estas medidas puede consultarse: Puelma Accorsi, A. (2001), Sociedades, Ed. Jurídica de Chile, 2001; VÁsquez Palma, Fernanda M. (2013), Sociedades. Comerciantes, empresas, grupos de empresas y otros sujetos del Derecho Comercial, Santiago de Chile, Ed. LegalPublishing-Thomson Reuters.

12 Ley No 20.494, Agiliza trámites para el inicio de actividades de nuevas empresas, publicada en el Diario Oficial el 27 de enero de 2011.
} 
nos, y a la necesidad de publicación en el Diario Oficial en el caso de constitución, modificación o disolución de una figura societaria, de manera tal que el proyecto de ley buscaba facilitar la apertura e iniciación de empresas de todos los tamaños en su primer contacto con las autoridades comunales, esto es, las Municipalidades y el Servicio de Impuestos Internos.

Luego de una breve discusión, el proyecto se aprobó en enero de 2011. El texto legislativo introduce modificaciones en la Ley de Rentas Municipales, en el Código Tributario y en la Ley sobre Impuesto a las Ventas y Servicios, incorporando una serie de medidas que apuntan a los objetivos trazados.

\section{2.) LEY 20.659}

Esta ley tuvo como antecedente la estimación del ejecutivo que en el procedimiento de constitución de sociedades no se habían aprovechado las ventajas que proporcionan las nuevas tecnologías de la información, apreciación que se plasma en el mensaje con que se inició la tramitación del proyecto de la ley en cuestión, de fecha 29 de octubre de $2010^{13}$.

Refiriéndose al sistema vigente, el documento hace presente que los procedimientos para establecer una nueva empresa o unidad económica organizada, requiere de trámites que implican varias etapas, que consumen tiempo y recursos, y que son igualmente exigidos en caso que se pretenda celebrar otros actos jurídicos tales como modificar, transformar, fusionar, dividir, terminar o disolver personas jurídicas de ese tipo, lo que implica asumir altos costos directos e indirectos ${ }^{14}$.

En vista de lo anterior, el Ejecutivo sostuvo que ante estas solemnidades era posible utilizar otros mecanismos que igualmente permitiesen asegurar la fe pública que envuelve la constitución de una persona jurídica, aprovechando el uso de las tecnologías y la eliminación de ciertos trámites. El modelo creado se dirige principalmente a facilitar la constitución de sociedades en sectores que actualmente funcionan fuera del sistema, como microemprendimientos que se mantienen en el mercado informal ${ }^{15}$. En lo fundamental, se propone que la constitución de una

13 Historia de la Ley No 20.659, Biblioteca del Congreso Nacional de Chile. En http://www. leychile. cl/consulta/portada_hl?tipo_norma=xx1\&nro_ley=20659\&anio=2013 [visitado el 16/07/2013].

14 Bajo este entendido, los estudios realizados arrojaron que los costos para la creación de una empresa ascienden aproximadamente a $\$ 250.000$ para el caso de las microempresas, $\$ 315.000$ para las pequeñas empresas, $\$ 410.000$ para las empresas medianas y $\$ 520.000$ para las empresas grandes, aproximadamente

15 De acuerdo a los antecedentes del SII, para el año 2008, de las 900.375 empresas registradas en el SII, un $69 \%$ correspondía a personas naturales constituidas como empresarios individuales y el restante $31 \%$ a sociedades. En el caso de las microempresas este porcentaje alcanzaba al $80 \%$, en las pequeñas al $42 \%$, en las medianas al 13\%, y en las grandes empresas al $3 \%$. 
sociedad se pueda realizar por medio de la suscripción de un formulario electrónico que comprenda todos los campos obligatorios que la ley exige para dicha forma societaria y que esta se incorpore de inmediato y en forma gratuita a un Registro de Sociedades electrónico. Similar procedimiento podrán utilizar para la modificación, fusión, división, entre otras, las sociedades afectas a esta normativa ${ }^{16}$.

Fue así como se dictó la Ley en comento cuyo artículo segundo transitorio fijó su entrada en vigencia para el primer día hábil del mes subsiguiente al de la publicación del reglamento en el Diario Oficial ${ }^{17}$. En cuanto a la disminución de costos, se agrega la creación del Decreto Exento Núm. 339 de la Subsecretaría de Economía y empresas de menor tamaño del Ministerio de Economía, Fomento y Turismo, de 9 de abril de 2013, que fijó tarifas por el cobro del estampado de la firma electrónica por parte de los notarios públicos del país, en la aplicación de la ley 20.659.

Los beneficios esperados de la legislación en comento serían los siguientes:

i) Constitución de empresas y sociedades en un solo trámite, incluyendo escritura, registro, publicación, obtención de RUT e iniciación de actividades, al encontrarse el registro que lleva el Ministerio de Economía al efecto, coordinado con el sitio electrónico del Servicio de Impuestos Internos;

ii) La constitución, modificación, fusión, división, terminación y disolución de sociedades se podrán hacer en línea, desde la propia casa o del domicilio de la empresa, si el emprendedor posee firma electrónica avanzada, o bien desde una notaría, si no la tiene;

iii) Acceso público y gratuito para conocer el estado de empresas y sociedades;

iv) Mejoramiento sostenido en las clasificaciones internacionales para la creación de empresas y apertura de nuevos negocios, lo que nos hace más atractivos y competitivos frente a los inversionistas ${ }^{18}$.

16 Véase: http://legislativo.votainteligente.cl/proyectoley/show/id_proyecto_ley/7486.

17 El Reglamento se fijó mediante el Decreto Supremo No 45 del Ministerio de Economía, Fomento y Turismo, publicado en el Diario Oficial el 28 de marzo de 2013. El artículo segundo transitorio del Reglamento, sin embargo, estableció su entrada en vigencia en forma gradual para cada forma societaria.

18 Ventajas fueron así expuestas por el señor Ministro de Economía en la Comisión de Economía del Senado durante el trámite legislativo del proyecto de ley. 


\section{2) ANÁliSIS DE LAS REFORMAS LEGISLATIVAS}

\section{1.) PRINCIPALES ASPECTOS DE LA LEY 20.494}

\subsection{1.) Ámbito de aplicación subjetiva}

La modificación establecida por la ley No 20.494 es aplicable a todas las personas jurídicas de derecho privado, de manera tal que no solo las sociedades comerciales quedaron comprendidas en ella, sino también otras personas jurídicas de esta naturaleza, como una corporación o fundación.

\subsection{2.) Ámbito de aplicación objetiva}

Se trata de una modificación que tiende a la simplificación de la constitución societaria sobre aspectos tributarios, de patentes municipales y de publicación en el Diario Oficial. Rige para todas las sociedades, a diferencia de la ley 20.659.

\subsection{3.) Modificaciones legislativas}

Se modifica el artículo 26 del Decreto Ley $\mathrm{N}^{\circ} 3.063$, de 1979, sobre Rentas Municipales, para establecer la obligación de las municipalidades de entregar la patente respectiva (definitiva o provisoria) una vez que el contribuyente hubiere cumplido con los trámites señalados en dicha ley. Su objetivo no es otro que evitar la dilación en el inicio de las actividades empresariales.

Por otra parte, los contribuyentes que opten por la facturación electrónica tendrán derecho a que el SII les autorice en forma inmediata el inicio de actividades y la emisión de los documentos tributarios electrónicos que sean necesarios para el desarrollo de su giro o actividad. Para ejercer esta opción deberá darse aviso al Servicio en la forma que este determine. En el caso de los contribuyentes que soliciten por primera vez la emisión de dichos documentos, la autorización procederá previa entrega de una declaración jurada simple sobre la existencia de su domicilio y la efectividad de las instalaciones que permitan la actividad o giro declarado, en la forma en que disponga el Servicio de Impuestos Internos.

Finalmente, se autoriza a sustituir la publicación en el Diario Oficial de la constitución, modificación y disolución de sociedades, por su publicación en la página web del mismo Diario Oficial que se implementará al efecto. Es gratuita la publicación de extractos para todas las empresas de hasta 5.000 UF de Capital. Para las demás, tiene un costo de 1 UTM por cada extracto. 


\section{2.) PRINCIPALES MODIFICACIONES REALIZADAS POR LA LEY 20.659}

\subsection{1) Ámbito de aplicación subjetiva}

De acuerdo a su título, esta ley simplifica el régimen de constitución, modificación y disolución de las sociedades comerciales; sin embargo, si revisamos el elenco señalado en su Art. $2^{\circ}$, vemos que esta norma también se aplica a una sociedad civil, como es la SRL y a las personas jurídicas que no son sociedades, como ocurre con la EIRL.

En efecto, de acuerdo al precepto en cita, el ámbito de aplicación es el siguiente:

- La empresa individual de responsabilidad limitada, regulada por la ley $\mathrm{N}^{\circ} 19.857$;

- La sociedad de responsabilidad limitada, contemplada en la ley $\mathrm{N}^{\circ} 3.918$;

- Sociedad anónima cerrada, establecida en la ley $N^{\circ} 18.046$;

- Sociedad anónima de garantía recíproca, regulada por la ley $\mathrm{N}^{\circ}$ 20.179;

- Sociedad colectiva comercial, contemplada en los Párrafos 1 a 7 , ambos inclusive, del Título VII del Libro II del Código de Comercio;

- Sociedad por acciones, establecida en el Párrafo 8 del Título VII del Libro II del Código de Comercio;

- Sociedad en comandita simple, contemplada en los Párrafos 10 y 11 del Título VII del Libro II del Código de Comercio;

- Sociedad en comandita por acciones, establecida en los Párrafos 10 y 12 del Título VII del Libro II del Código de Comercio ${ }^{19}$.

Desde una perspectiva negativa, no se aplica a las sociedades anónimas abiertas o especiales, como tampoco a las sociedades legales mineras y a otras personas jurídicas no societarias. En tal sentido, el ámbito de aplicación de la ley No 20.659, es más reducido que la ley No 20.494 .

\subsection{2.) Ámbito de aplicación material}

En lo esencial se establece que la constitución de una sociedad, y los actos que puedan tener lugar tras su incorporación, se puedan realizar por

19 Debemos tener en cuenta que, según lo establecido en el artículo $2^{\circ}$ transitorio, actualmente, a través de la ley 20.659 solo se pueden crear sociedades de responsabilidad limitada, así la creación de otro tipo de sociedades se encuentra diferida en el tiempo: Sociedad de Responsabilidad Limitada (mayo de 2013), Empresa Individual de Responsabilidad Limitada (octubre de 2013), Sociedad por Acciones (junio de 2014), Sociedad Colectiva Comercial, Sociedad en Comandita Simple y Sociedad en Comandita por Acciones (junio de 2015), Sociedad Anónima Cerrada y Sociedad Anónima de Garantía Recíproca (junio de 2016). 
medio de la suscripción de un formulario electrónico, el que comprende todos los campos obligatorios que por ley debe cumplir dicha forma societaria. El formulario será de libre acceso, estará disponible en un sistema que tendrá cobertura a nivel nacional, las 24 horas del día y los 7 días de la semana, en el sitio web gratuito del Ministerio de Economía.

\subsection{3.) Carácter voluntario}

Las disposiciones de esta nueva normativa son de carácter optativo, lo que significa que las personas que deseen constituir una sociedad podrán optar por el Régimen General o por el Régimen Simplificado, de manera que ambos sistemas coexistirán en paralelo ${ }^{20}$.

\subsection{4.) Objetivos}

Por medio de esta ley se pretende simplificar el régimen de constitución, modificación, y disolución de las sociedades y personas jurídicas a las que nos hemos referido precedentemente, que opten por este nuevo sistema, y a las constituidas con anterioridad a ella que decidan migrar al nuevo régimen simplificado.

La simplificación introducida por la ley consiste en eliminar las solemnidades establecidas legalmente, eliminando con ello los costos derivados de la constitución, modificación o disolución tradicional de las sociedades. El Estado asume un carácter tutelar de estos actos en aras de facilitar el emprendimiento y con ello al crecimiento económico.

\subsection{5.) Operatividad por medio de formularios}

La forma que la ley establece para constituir, modificar y disolver una sociedad es por vía de formularios electrónicos. En efecto, de acuerdo al Art. 19, letra e), inciso final, del Reglamento se establece que " $L a$ inscripción de los formularios reemplaza, respecto de las personas juridicas que se acojan a la ley, las solemnidades de otorgamiento de escritura pública, inscripción y publicación de extractos requeridos por las leyes que las regulan".

20 La Migración que define el art. $3^{\circ}$ No $5^{\circ}$ de la ley, es de carácter recíproca, lo que también es clara señal que la nueva normativa legal es de carácter optativo. También se deduce el carácter optativo de la ley en cuestión, de las definiciones de "Régimen General” y "Régimen Simplificado", que nos da el art. 20 números 14 y 15, respectivamente, del Reglamento de la ley. En efecto, el primero define el Régimen General como "El sistema de constitución, modificación, transformación, fusión, división, terminación o disolución de una persona jurídica conforme a las solemnidades requeridas en las leyes que la establecen y regulan". Por su parte, el segundo número define el Régimen Simplificado, como "El sistema de constitución, modificación, transformación, división, fusión, terminación y disolución de una persona jurídica establecido en la ley y este reglamento, así como su migración hacia o desde el Régimen General". 
De conformidad a lo dispuesto en el inc. 2 del art. 6 de la ley en cuestión, en los formularios hay menciones obligatorias y voluntarias. Son obligatorias, aquellas que las leyes exijan para la validez del acto respectivo, las segundas podrán ser completadas voluntariamente por el o los suscriptores del formulario. Son de carácter obligatorio todos los campos necesarios para completar las menciones esenciales que las leyes establecen para efectuar cada una de las actuaciones. Considera además esenciales, las menciones de la cédula de identidad sea nacional o para extranjeros, según corresponda y una dirección de correo electrónico para cada titular. En relación a los campos voluntarios, el Reglamento dispone que si no son completados, se entenderá que a su respecto rigen las normas supletorias de las leyes que regulen dichas actuaciones. Agrega el Reglamento que los formularios contendrán campos en que los usuarios podrán agregar las menciones accidentales que estimen pertinentes. De este modo, se conserva la tradicional distinción de elementos esenciales, de la naturaleza y accidentales, aunque no con total sintonía respecto de las normas legales.

En relación a los aportes, el Art. 8 de la ley dispone que cuando se requiera de formalidades o solemnidades especiales, aquel deberá efectuarse conforme a ellas. Así, si a una sociedad se está aportando un bien raíz los socios deberán recurrir a una escritura pública y la correspondiente tradición en el Conservador de Bienes Raíces respectivo. Mientras no se dé cumplimiento a ello los pactos no producirán efecto contra terceros, sin perjuicio de las demás sanciones que dispongan las leyes que establecen y regulan a las respectivas personas jurídicas.

En tal sentido, además de los formularios, el sistema admite otras formas de actuación, como ocurre con la utilización de los denominados "Documentos Registrables", que dice relación con que los usuarios puedan incorporar al Registro, escrituras públicas o cualquier otro tipo de instrumento público, documentos protocolizados, documentos oficiales emitidos por autoridades nacionales o extranjeras legalizados y protocolizados en Chile que sea complementario a una actuación, o donde conste un acto referido a una persona jurídica inscrita en el Registro, pero distinto a una actuación que se realice o deba realizarse mediante formulario. La digitalización de dichos documentos, debe realizarse ante notario, con el objeto de certificar que la copia digital del documento es fiel a su original. El caso más común de documento registral, y que debe siempre ser registrado, es aquel donde conste la personería del representante o apoderado del o los titulares para realizar actuaciones en el registro.

El Reglamento dispone que los formularios podrán ser suscritos por los interesados solo cuando se ha ingresado la información requerida en los campos obligatorios. La suscripción de ellos se realizará mediante la firma del constituyente, socios o accionistas, según el caso, a través de la 
firma electrónica avanzada de estos o ante un Notario Público, en el caso que los usuarios no cuenten con esa firma o no deseen hacer uso de ella, o bien cuando una persona jurídica concurra a la suscripción representado ${ }^{21}$. La suscripción de los formularios por todos los socios o accionistas deberá efectuarse en el plazo de sesenta días contado desde la firma del primero de ellos. En caso contrario, se tendrá por no efectuado para todos los efectos.

\subsection{6.) Creación de un Registro de empresas y sociedades}

Una vez suscrito el formulario, la sociedad se incorporará automáticamente en el Registro de Empresas y Sociedades a cargo del Ministerio de Economía, Fomento y Turismo. La creación de este registro es otra de las novedades de esta ley, en él se pueden incorporar los instrumentos ligados a la constitución, modificación, fusión, transformación, división, terminación o disolución de una sociedad que al efecto se presente, como además las sentencias u otra resoluciones judiciales que causen ejecutoria y que ordenen la disolución o modificación o cualquier otra resolución judicial referida a una persona jurídica incorporada al Registro ${ }^{22}$.

De conformidad al Art. 11 de la citada norma, se trata de un registro electrónico que deberá constar en un sitio web, al que deberán incorporarse las personas jurídicas que se acojan a este régimen. Este registro deberá estar permanentemente actualizado a disposición de quien lo consul-

21 Es importante destacar que el proyecto original contemplaba que si el contribuyente no tenía firma electrónica avanzada, podía suscribir los formularios mediante la firma electrónica ante el funcionario del Servicio designado al efecto o ante un Notario. El art. 10 del proyecto original en su inc. $3^{\circ}$ decía "El constituyente, socio o accionista que no cuente con firma electrónica avanzada podrá suscribir los formularios mediante la firma de estos ante el funcionario del Servicio que haya sido designado al efecto, quien tendrá el carácter de ministro de fe, o también ante un Notario". Esta situación fue objeto de reparos ya en el primer informe de la Comisión de Economía, sosteniéndose la inconveniencia de imponer a un funcionario del Servicio de Impuestos Internos la obligación de desempeñarse como Ministro de Fe, sin que tenga la competencia para ello. En virtud de ello el Ejecutivo presentó una indicación sustitutiva del texto del proyecto, excluyendo la posibilidad que tenga la calidad de ministro de fe un funcionario del SII. Historia de la Ley No 20.659.

22 El proyecto de ley originalmente presentado al Congreso Nacional contemplaba que fuera el Servicio de Impuestos Internos quien administrara los formularios y llevara el registro y portal para la constitución de empresas en forma simplificada. Sin embargo, durante el trámite legislativo el Ejecutivo tuvo que modificar la iniciativa, para trasladar tales responsabilidades al Ministerio de Economía toda vez que se presentaron, por distintos personeros de la sociedad civil, academia, banca, etc. diversos reparos relacionados con la figura y rol que cumpliría el Servicio de Impuestos Internos (SII) bajo el proyecto original. Básicamente los reparos se fundaban en que la función del referido Servicio consiste en ocuparse de la recaudación, control y fiscalización de los tributos, siendo evidente que su misión esencial apuntaba en una dirección completamente distinta a la contemplada en la iniciativa legal original. 
te, de manera que asegure la fiel y oportuna publicidad de la información incorporada en él.

El Manual de Operaciones establecido en el Decreto Supremo No 45 de 2013, que aprueba el Reglamento de la Ley 20.659 dispone que los usuarios pueden ingresar al Registro de Empresas, indistintamente a través de las siguientes direcciones: www.registroempresas.cl, www.tuempresaenundía.cl, www.registrosociedades.cl, www.registrodeempresas.cl, y www.registrodesociedades. $\mathrm{cl}^{23}$.

Se trata de un registro público y gratuito, tanto respecto de la realización de actuaciones relativas a personas jurídicas, así como para las consultas al sistema y emisión de certificados. Es además un registro único, lo que significa que existirá un solo registro a nivel nacional y no uno por cada región, ciudad o comuna, como ocurre actualmente con notarios y conservadores; y cuyo objeto es dar publicidad de todas aquellas actuaciones que en él se realicen, reemplazándose así la publicación en el Diario Oficial, como se establece expresamente en el artículo 21 de la ley. Finalmente, toda inscripción o anotación respecto de una persona jurídica quedará registrada en el mismo, con el objeto de tener información histórica de cada una de las personas incorporadas a este

Este Registro está pensado para sustituir con el tiempo al Registro de Comercio del Conservador de Bienes Raíces. Además, se establece que por el solo hecho de la publicación de los formularios en el Registro de Empresas y Sociedades, el SII se entenderá informado para todos los efectos legales y deberá otorgar un rol único tributario correspondiente, sin más trámites ${ }^{24}$.

23 El Manual de Operaciones que establece el Reglamento de la Ley No 20.659, fue aprobado por Resolución Exenta No 10858, del 10 de Mayo de 2013, del Subsecretario de Economía y Empresas de Menor Tamańo, En http://www.tuempresaenundia.cl/docs/ManualOperativo.pdf [visitado el 21/7/2013].

24 Al respecto, la Circular $\mathrm{N}^{\circ} 23$, del Depto. de administración y asistencia de contribuyentes del S.I.I., de fecha 3 de mayo de 2013, señala al respecto: La solicitud de inscripción en el Rol Único Tributario (RUT), tratándose de la constitución de personas jurídicas acogidas a esta nueva ley, se entenderá efectuada por el solo hecho de suscribir el formulario respectivo que realizan el constituyente, socios o accionistas, a través del portal web del Ministerio de Economía, Fomento y Turismo, y que se incorpora para dichos efectos en el Registro. Hecho lo anterior, en forma simultánea, a través del mismo portal, el Servicio asignará un RUT a la persona jurídica que se constituya mediante dicho régimen, desplegando un mensaje que indicará el número respectivo de este. Los socios o representantes legales que constituyan una sociedad acogida a la citada Ley, podrán optar por efectuar el trámite de Aviso de Inicio de Actividades, inmediatamente después de su constitución. Para dicho efecto, el mensaje en el que se despliega el número de RUT asignado, contendrá un enlace al portal del Servicio, en el cual los suscribientes podrán impetrar dicha solicitud. Los contribuyentes que no realicen el inicio de actividades en la forma descrita, podrán optar por efectuar dicho trámite a través del sitio web del Servicio. 


\subsection{7.) Migración}

Como señalamos, la ley 20.659 no deroga el régimen general de constitución, modificación, fusión, transformación, división, terminación o disolución de sociedades, sino que establece un sistema alternativo y paralelo. A partir de ello, los socios o accionistas pueden optar entre las diversas normativas en la medida en que van a realizar dichos actos. Una vez constituidas, las personas jurídicas podrán transitar desde el sistema registral conservatorio al sistema establecido en la ley 20.659 y viceversa ${ }^{25}$.

La migración al nuevo sistema debe ser acordada por la totalidad de los titulares de los derechos sociales, salvo que se señale algo distinto en el contrato o estatutos de la sociedad. Para el caso de sociedades cuyos acuerdos deban adoptarse por juntas, esta debe ser aprobada por mayoría absoluta de las acciones emitidas con derecho a voto. El acta de la misma deberá ser reducida a escritura pública, siendo una copia digital íntegra de ella incorporada al Registro, pero en caso que la totalidad de los socios o accionistas suscriben el formulario de migración no será necesario cumplir con dichos requisitos. Para realizar la migración debe el titular o titulares de los derechos sociales o la persona que designe la junta de accionistas en que se acordó la migración, o los representantes de estos o de la sociedad, solicitar al Conservador de Bienes Raíces respectivo la emisión de un certificado para migración. Dicho certificado, debe contener el extracto de los estatutos sociales. Una vez emitido el certificado debe anotarse la emisión del mismo al margen de la inscripción de la sociedad en el Registro de Comercio. Desde el momento de la anotación, no podrán realizarse nuevas anotaciones, inscripciones o subinscripciones a esta. A contar de la emisión del certificado, quien lo haya solicitado tendrá un plazo de 30 días para suscribir el formulario de migración y acompañar una copia digital de dicho certificado. Hecho ello, el Registro enviará electrónicamente al Conservador de Bienes Raíces un certificado, debiendo este último anotar al margen de la inscripción del Registro de Comercio, que la sociedad se encuentra inscrita en el nuevo Registro. Si transcurren más de 35 días desde que el Conservador de Bienes Raíces haya emitido el certificado correspondiente, sin que se le haya comunicado de la incorporación de la sociedad en el nuevo Registro, caducará el certificado emitido por aquel, pudiendo en dicho caso continuar haciéndose inscripciones y anotaciones en el Registro de Comercio.

La migración del nuevo Registro será obligatoria cuando se dejen de cumplir los requisitos para estar inscrito en el nuevo sistema, como

25 Al respecto, la posibilidad de migrar las sociedades de responsabilidad limitada existe solo a contar de octubre de 2013, respecto a los otros tipos societarios, estos pueden migrar en la misma fecha en que comenzará a regir para ellos la ley 20.659. 
es el caso de una sociedad anónima cerrada que pasa a ser abierta. En este caso, la sociedad debe migrar en el plazo de 60 días desde que se produjo el hecho por el que dejaron de cumplir con los requisitos. Para esto, se deberá suscribir el formulario de migración al régimen general, por todos los titulares de los derechos sociales, o sus apoderados o representantes, en su caso, o por la persona designada para estos efectos por la junta de accionistas. De acuerdo a la ley, en esta caso, la migración también deberá aprobarse por la totalidad de los titulares de los derechos sociales, y en el caso de sociedades cuyos acuerdos deban adoptarse por juntas, por mayoría absoluta de las acciones emitidas con derecho a voto, debiendo el acta acompañarse de la misma forma que para la migración al nuevo sistema, salvo la suscripción por la unanimidad de los socios o accionistas.

Finalmente, es preciso señalar que una sociedad no podrá registrar actos en uno y otro registro, toda vez que la normativa contempla que una empresa constituida en un sistema, no pueda registrar actos en el otro.

Es importante destacar que en el proyecto original no estaba considerada la posibilidad de cambiarse voluntariamente desde el nuevo sistema al tradicional.

\subsection{8.) Saneamiento de la nulidad de las personas jurídicas a que se refiere la ley}

De acuerdo al Art. 16 de la ley, para efectos del saneamiento de la nulidad derivada de vicios formales que afecten la constitución, modificación, transformación, división, fusión, terminación o disolución de las personas jurídicas acogidas a esta ley, el titular o, en su caso, quienes sean los titulares de los derechos sociales o acciones de la sociedad al tiempo del saneamiento respectivo, o sus representantes o apoderados para estos efectos, deberán corregir el formulario en que conste el vicio y suscribirlo de conformidad a las normas señaladas en el Título II de esta ley. Si el vicio incide en una cesión de derechos sociales, deberán concurrir a la suscripción del formulario, además, el cedente o sus causahabientes y quienes al tiempo del saneamiento sean los titulares de los derechos materia de la cesión.

En los casos en que se requiera adoptar acuerdos sobre el saneamiento de la nulidad por medio de la celebración de una junta, el acta que se levante, previo cumplimiento de las formalidades que sean necesarias, deberá ser reducida a escritura pública. Una copia digital íntegra de aquella deberá incorporarse al Registro bajo el número de identificación de la persona jurídica respectiva. Con todo, no se requerirá del acta ni de su incorporación al Registro, si la totalidad de los socios o accionistas suscriben el formulario correspondiente. El procedimiento establecido sustituye el establecido en la ley 19.499 en todo lo que sea contrario a esta ley. El 
saneamiento del vicio de nulidad producirá efecto retroactivo a la fecha de la incorporación del formulario rectificado en el registro.

\subsection{9.) Principios que rigen el sistema}

De acuerdo al Art. 3 del Reglamento, los principios que rigen el sistema simplificado establecido por la Ley 20.659, son los siguientes:

a) Gratuidad. La incorporación de las actuaciones y documentos registrables en el Registro y el acceso a la información, son gratuitos.

b) Seguridad de información. El Administrador del Registro deberá velar de manera permanente por la seguridad e integridad de la información contenida en este.

c) Publicidad de la información y Protección de Datos. La información incorporada en el Registro será esencialmente pública. Con todo, el Administrador del Registro velará porque la transmisión de datos personales contenidos en el Registro, en lo que fuere aplicable, cumpla con las disposiciones establecidas en la ley No 19.628, sobre protección de la vida privada.

\section{3) EVALUACIÓN DE LAS LEYES EN SU APLICACIÓN PRÁCTICA 26}

\section{1.) LEY 20.494}

El Ministerio de Economía, Fomento y Turismo ha entregado las siguientes cifras respecto al período 2012:

- La ley 20.494 disminuyó los costos en la creación de empresas en un $25 \%$.

- Redujo de 22 a 7 los días requeridos para crear una empresa.

- El crecimiento de las sociedades constituidas como personas jurídicas aumentó en un 32\% el 2011.

- $\quad 15,8 \%$ es el crecimiento anual en diciembre de 2012 (6.550 sociedades se constituyeron en diciembre de 2012 en relación a las 5.655 de un año atrás).

- $\quad 17,2 \%$ es el crecimiento durante el año 2012 (68.439 sociedades se constituyeron ese año, en relación a las 58.407 del 2011, marcando un récord histórico en el denominado año del emprendimiento).

26 Basado en los boletines de Constitución de Sociedades de diciembre 2012 y marzo 2013, elaborados por el Ministerio de Economía, Fomento y Turismo, disponibles en www.economia.gob.cl (Visitado el 18 de agosto de 2013). 
- Permitió avanzar en el ranking Doing Business 2013, del lugar 62 pasó al 37 (de 185 países en el ranking) quedando primero dentro de América Latina y el Caribe.

La constitución de empresas en el Diario Oficial aumentó en noviembre de 2011 a un 17,7\% respecto a igual mes del ańo anterior $(6.157$ constituciones de sociedades) y en diciembre del mismo año a un $15,8 \%$ sobre igual mes del año anterior (con 6.550 constituciones de sociedades). En el 2012 se produjo un aumento de un 17,2\%, correspondiendo a 68.439 empresas constituidas, muy por sobre las 58.407 del 2011. A partir de abril de 2012, luego del impacto de la ley 20.494, vuelve a la normalidad la constitución de empresas con tasas de crecimiento en torno al promedio histórico. No obstante, destacan los meses de junio, agosto, octubre y noviembre de dicho año por el aumento de sociedades constituidas de un $18,7 \%, 24,3 \%, 24,6 \%$ y $17,7 \%$, respectivamente.

En el siguiente gráfico podemos observar que con el antiguo procedimiento, la creación de empresas fue más o menos constante durante los años 1998 a 2010, manteniendo el crecimiento dentro de ciertos parámetros. La diferencia es notoria a partir del 2010 y 2011, donde el aumento es considerable luego de la entrada en vigencia de la ley 20.494 .

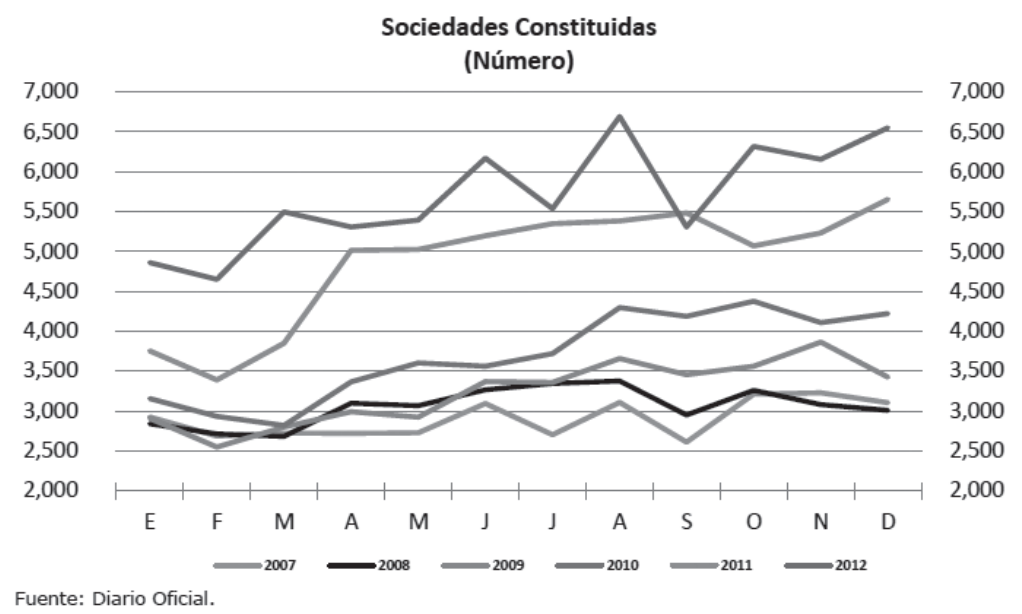

En el año 2012 se crearon 68.439 empresas con personalidad jurídica, superando las 58.407 del año 2011, de este modo se observó un alza de un $17,2 \%$ en la creación de empresas respecto al año anterior. Asimismo, en diciembre se crearon 6.550 empresas, lo que representa un aumento de $15,8 \%$ respecto a igual mes del año anterior ${ }^{27}$.

27 En cuanto a los efectos derivados de esta ley, en Sercotec destaca el importante aumento en recursos destinados a empresas de menor tamaño a través del capital semilla y capital abeja, aumentando en cerca de un $90 \%$ los beneficiarios del capital semilla. Por su parte, en CORFO 


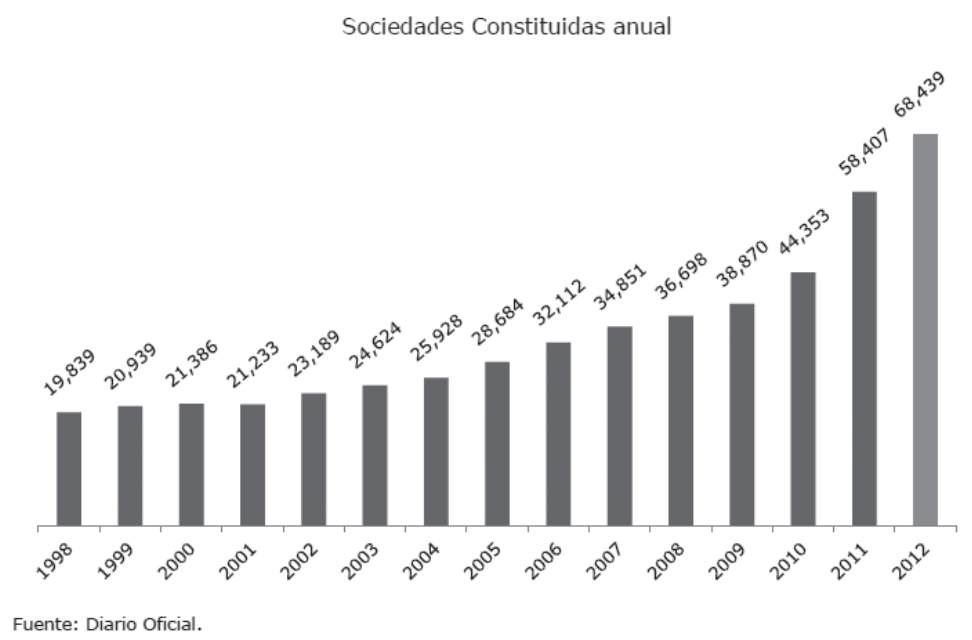

\section{2.) LEY 20.659}

Con la entrada en vigencia de la ley $20.659^{28}$, se observó que la constitución de empresas aumentó en un $40 \%$ en el primer mes de su implementación, respecto a igual mes del año anterior (con 7.549 constituciones de sociedades, donde 1.729 provienen del registro de empresas del Ministerio de Economía y 5.820 restantes provienen del registro del Diario Oficial).

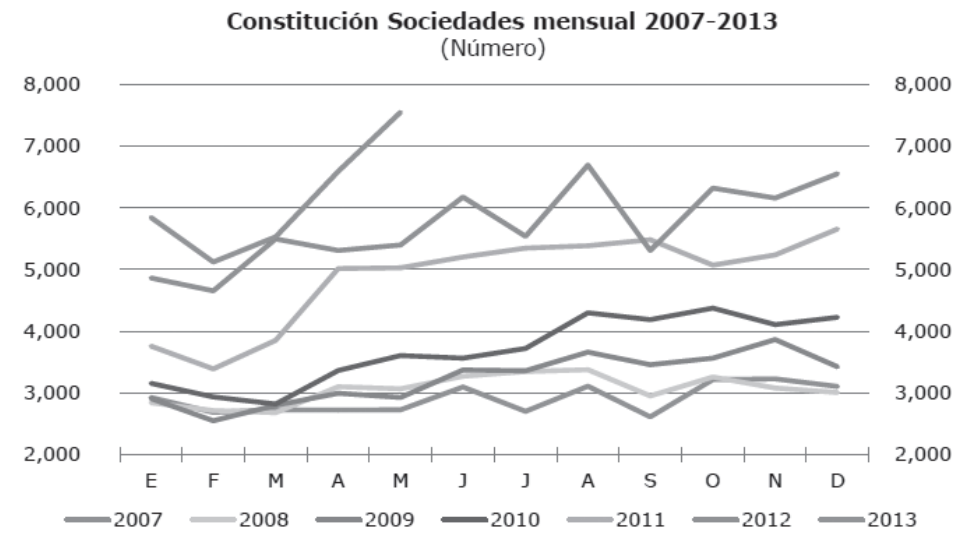

Fuente: Ministerio de Economía y Diario Oficial.

destaca el importante aumento de las garantías de operaciones crediticias. Desde el 1 de enero hasta el 30 de noviembre de 2012 se han otorgado 73.068 Garantías CORFO en operaciones crediticias por más de US\$3.548 millones, con lo que se ha incrementado casi 2 veces el número de garantías entregadas respecto al año 2011. Más del 80\% de las garantías ha ido a las micro y pequeñas empresas. El número de garantías otorgadas a la fecha, ha superado con creces la meta de 60.000 operaciones crediticias para este año por parte de CORFO. 
En el siguiente gráfico se advierte el incremento en la constitución de empresas, mediante la comparación de los meses de mayo de cada año desde 2007 a 2013.

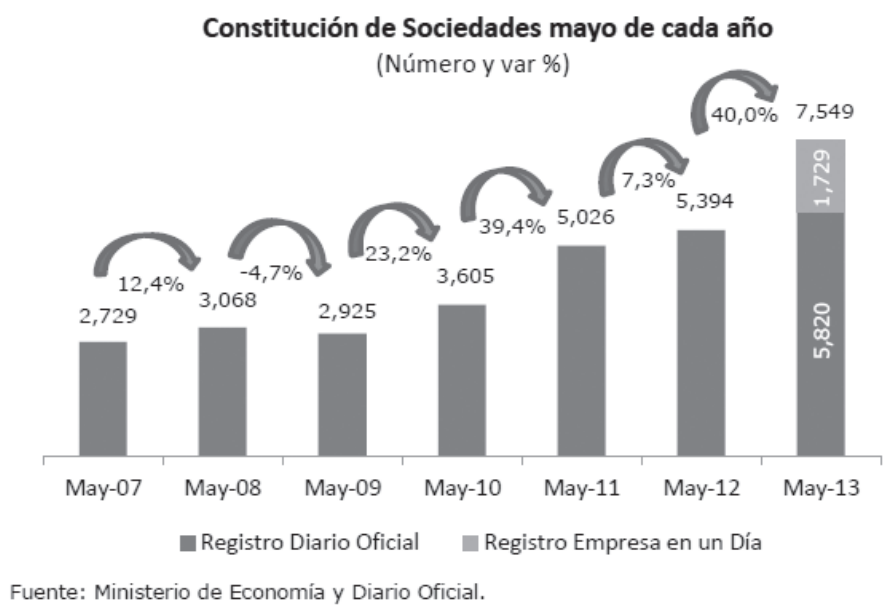

De 5.394 sociedades constituidas en el año 2012, estas aumentan a 5.820 el ańo 2013.

Con la implementación de la Ley 20.659 este aumento exponencial en la constitución de nuevas sociedades se ha acentuado, por lo menos en los primeros meses de vigencia ${ }^{29}$. En efecto, de acuerdo a las cifras del Ministerio de Economía, la mayoría de las empresas que se forman en Chile son sociedades de responsabilidad limitada (S.R.L.). En la siguiente tabla se presenta una comparación entre el número de S.R.L. que se han creado desde el año 2010 al 2013, en relación a otros tipos de sociedades, donde se aprecia el aumento de las mismas en el año 2013.

CONSTITUCIÓN SOCIEDADES

(Número, participación \% y crecimiento)

S.R.I.

Otro tipo

Total

Período No \% Part. Crec. No \% Part. Crec. No Crec.

$\begin{array}{llllllllr}\text { May-10 } & 2.219 & 62 & & 1.385 & 38 & & 3.604 & \\ \text { May-11 } & 3.048 & 61 & 37 & 1.972 & 39 & 42 & 5.020 & 39 \\ \text { May-12 } & 2.920 & 54 & -4 & 2.474 & 46 & 25 & 5.394 & 7 \\ \text { May-13 } & \mathbf{4 . 5 6 4} & 60 & \mathbf{5 6} & 2.985 & 40 & \mathbf{2 1} & \mathbf{7 . 5 4 9} & \mathbf{4 0}\end{array}$

Fuente: Diario Oficial y Ministerio de Economía

29 Además de los informes de mayo y junio publicados en el Ministerio de Economía, no se han dado a conocer más resultados sobre esta materia. 
En cuanto a la utilización del registro de empresas, también se advierte un aumento considerable. Así, en los primeros cinco días de funcionamiento se constituyeron 25 empresas, mientras que en la quinta semana se llegó a 505 empresas. Además, se observó un incremento en la participación del nuevo sistema en la constitución total de sociedades de responsabilidad limitada. Así, en los primeros cinco días, un 5\% de las nuevas SRL fueron constituidas en el registro de empresas, mientras que en la quinta semana el nuevo sistema representaba un $50 \%$ de las nuevas sociedades.

Otros datos que pueden destacarse, luego del primer mes de funcionamiento de la ley (mayo y junio 2013), son los siguientes ${ }^{30}$ :

- El sitio web cuenta con más de 21.000 usuarios registrados.

- Las cifras muestran que se constituyeron 82 sociedades al día en promedio (1782 en total durante el mes de mayo).

- Un 20\% de las nuevas empresas realizó su constitución con firma electrónica avanzada, mientras que un $80 \%$ restante debió acudir a un notario.

- Si los usuarios cuentan con firma electrónica avanzada el costo es cero pesos, mientras que si no tiene firma electrónica debe cancelar $\$ 6.000$ para que un notario certifique la firma.

- Las empresas formadas tienen 2 socios en promedio: Las nuevas sociedades tienen entre 2 y 5 socios, y uno de ellos es mujer (33\%).

- El capital más frecuente en las nuevas empresas es $\$ 1.000 .000$. El promedio de estos capitales oscila en $\$ 4.000 .000$.

- El rubro de actividad más frecuente de las empresas que se crean en el sistema y que han iniciado actividades en el SII son Obras Menores en Construcción (Contratistas, Albañiles, Carpinteros), Servicios Integrales de Informática, Servicios de Ingeniería Prestados por Empresas N.C.P2 y Obras de Ingeniería.

- $\quad$ El 58\% de las sociedades constituidas tienen domicilio en la Región Metropolitana y un $42 \%$ en el resto del país. Las regiones de Valparaíso, Maule y Biobío son las que siguen a la Región Metropolitana con un $9,1 \%, 4,4 \%$ y $6,0 \%$, respectivamente.

Con las leyes en referencia, Chile ha logrado avanzar en el Ranking Doing Business, pasando del lugar 69 al 37, acercándose a las cifras establecidas por la OCDE.

30 Véase Boletines Empresas (mayo y junio) en un día publicado en: http://www.economia. gob.cl/constitucion-de-empresas-en-1-dia/ (visitado el 18.08.2013) 


\section{“RANKING DOING BUSINESS 2012-2013":}

Apertura de un negocio: Ranking 37

Procedimientos (número)

Tiempo (días)

Costo (\% de ingreso per cápita)

Requisito de capital mínimo

pagado

(\% de ingreso per cápita)
Chile América Latina OECD

$\begin{array}{rrr}7 & 9 & 5 \\ 8 & 53 & 12 \\ 4,5 & 33,7 & 4,5 \\ 0,0 & 3,7 & 13,3\end{array}$

\section{4) Algunos CUeSTIONAMIENTOS NECESARIOS}

1. ¿Se ha modernizado el Derecho societario chileno? Sí y no. Sí, porque a partir de las normas antes analizadas se ha logrado la simplificación de la constitución societaria, junto a otros actos de relevancia. El resultado de ello reside en un incremento del número de sociedades constituidas en Chile y, como corolario, nos hemos posicionado mejor en los rankings internacionales ${ }^{31}$ que miden estas variables. No, porque ambas leyes siguen el camino fragmentado que ha inundado el Derecho societario desde sus inicios legislativos, y como una consecuencia inevitable de ello, las reformas realizadas no han logrado atender los aspectos sustantivos más necesitados de cambios y modernización. De este modo, los cambios efectuados podrían calificarse como cosméticos si observamos las necesidades que verdaderamente plantea la modernización del Derecho societario. Esta labor aún no se ha realizado, de manera que estamos en deuda con este anhelo.

2. En este orden de ideas, la crítica más relevante que puede formularse sobre estas normativas, dicen relación con la falta de estudios jurídicos en su instauración, lo que se debe seguramente a la finalidad pretendida (económica). Como consecuencia de ello, un rol clave en su creación recayó en el Ministerio de Economía y no en la Cartera de Justicia.

Ello evidencia una concepción política particular del Derecho societario, en el sentido que se le concibe solo como un instrumento de creación de empresa, posición con la que ciertamente no puedo estar de acuerdo, pues ella desconoce y descuida el valor jurídico que la institución posee.

31 Doing Business. Banco Mundial IFC 2012 Haciendo negocios en un mundo más transparente. Comparación de la Regulación de las empresas locales de 183 economías, En: http:// espanol.dolingbusiness.org/media/FPDKM/Doing\%20Foreign/DB12-Business/Documents/Annual-Reports/Spanish.pdf. [visitado el 14/7/2013]. 
En tal sentido, si bien los objetivos eran encomiables, lo cierto es que nada impedía realizar una discusión más completa de los asuntos debatidos, integrando elementos jurídicos relevantes en su construcción.

Los avances parcelados que se han propiciado en la materia, provocan que hoy mantengamos un sistema de difícil lectura que llega a ser inconsistente en diversos aspectos. La discusión sustantiva habría colaborado a comprender y mejorar los problemas que todavía persisten en la institución societaria.

3. Ahora bien, en relación al contenido de la ley 20.659, es preciso considerar algunos rasgos particulares. En primer lugar, a diferencia de lo que acontece con otras legislaciones ${ }^{32}$, este sistema prácticamente no contiene limitaciones en cuanto a los tipos de sociedades que pueden formarse a través de este sistema. Ello, ciertamente, se vincula a lo anterior en la medida que no existen estudios ni fundamentos jurídicos que avalen esta posición.

Ello no es inocuo si se considera que la constitución de una sociedad no es un acto que pueda ser calificado como simple, pensemos por ejemplo en una sociedad anónima cerrada cuya normativa (Ley 18.046 y Reglamento respectivo) contienen una cantidad importante de normas imperativas. La complejidad de la misma nos lleva a preguntarnos si es posible que aquella se constituya por personas sin mayor preparación por medio de un formulario electrónico. En base a esta inquietud, quizás habría sido conveniente ajustar las posibilidades al objetivo pretendido por la ley, esto es, el emprendimiento de pequeños empresarios. En esta línea, podrían haberse acotado los tipos societarios, el monto máximo de aporte (como ocurre en la Ley 20.494), u otras características necesarias para operar en este sistema.

Adicionalmente, podemos observar diversas normas que se presentan confusas o redactadas con una inadecuada técnica legislativa, lo que refleja posibles inconsistencias y problemáticas que podrían haberse evitado con un diseño más jurídico.

4. Lo más característico de esta regulación es la utilización de los medios tecnológicos para constituir sociedades. Se trata de un sistema que se encuentra en concordancia con la ley 19.799 de 2002 sobre "Documento electrónico, firma electrónica y Servicios de Certificación de firma electrónica", en la medida que utiliza un "formulario electrónico" que debe ser suscrito por sus otorgantes mediante firma electrónica avanzada. En

32 España, por ejemplo, legisló sobre esta materia a partir de la Ley 7/2003 "Sociedad nueva empresa”, pero acotó esta posibilidad a las SRL y a las personas naturales, con un número de socios y monto mínimo de capital social particular. Otro tanto ocurre con la Ley 14/2013 sobre apoyo a los emprendedores y su internacionalización. 
tal sentido, jurídicamente se trata de un documento electrónico ${ }^{33}$, mas el legislador no otorga ni al formulario ni a su suscripción el carácter de instrumento público. Solo los certificados tendrán valor probatorio de instrumento público (Art. 22 de la ley). Una vez incorporado el documento suscrito por sus otorgantes al Registro, se entiende que la persona jurídica ha sido legalmente constituida, modificada o disuelta, según sea el caso (Art. $8^{\circ}$ del Regl.), sin necesidad de que la entidad verifique los antecedentes allí señalados.

La protección de la fe pública que envuelve la constitución de una persona jurídica ha quedado desplazada en importancia, lo que necesariamente provoca una distancia con el régimen clásico de constitución de empresas. Estimo que el sistema debió prever algún mecanismo de seguridad análogo en la creación de estas sociedades, tal como se dio a conocer en la iniciativa legal. Lo contrario provocará la coexistencia de dos tipos de sociedades (sociedades A y B), con variadas implicancias en el medio, principalmente relacionadas con el sistema financiero, crediticio y obligacional.

5. Ligado a lo anterior, debemos poner atención en el llenado del formulario. En tal sentido, los interesados que quieran constituir una persona jurídica de las enumeradas en la ley deberán ingresar a unos de los sitios web ya mencionados y completar cierta información requerida en algunos cuadros. Estos campos no presentan mayores limitaciones por lo que es relativamente sencillo cometer errores, por ejemplo, el sistema computacional actualmente vigente admite cualquier nombre, lo único que requiere es que se agregue la palabra "limitada". Ello contraría lo preceptuado en la ley 3.918 en su Art. $4^{\circ}$, que solo permite el nombre de uno o más socios o una referencia al objeto de la sociedad en su razón social. Como sabemos, tal mención es esencial, por lo que si existe un error en este punto la sociedad es nula.

Pues bien, aun cuando en el sitio web existe un recuadro que señala "debe incluir el rubro o el nombre de algunos de los socios. Ej. Agrícola Los Muermos Limitada", ello no representa un verdadero obstáculo, toda vez que si una persona inexperta introduce un nombre que no se condice con lo anterior, el sistema no necesariamente lo detecta y continúa sin mayor problema. De lo anterior resulta que esa leyenda como advertencia no es suficiente, de manera tal que el sistema implementado debiera corregirse en este punto.

Por otra parte, el recuadro correspondiente al objeto social tampoco es eficiente, pues aun cuando el sistema sugiere algunos giros sociales,

\footnotetext{
33 Definido por el Art. 2, d), de la citada ley como “Toda representación de un hecho, imagen o idea que sea creada, enviada, comunicada o recibida por medios electrónicos y almacenada de un modo idóneo para permitir su uso posterior".
} 
estos son demasiado específicos. El problema que se presenta es que las partes pueden escribir en dicho recuadro cualquier cosa como objeto social, incluso podrían establecer un objeto confuso, incompleto o ilícito y el sistema aceptarlo.

Existe, además, el casillero correspondiente a otros pactos que acuerden los socios que no se encuentra delimitado, lo que implica que una sociedad que se constituye pueda tener pactos eventualmente contradictorios que provoquen vicios de diferente naturaleza.

6. En este mismo orden de ideas, la nulidad de las sociedades constituidas por este mecanismo es otro de los aspectos que debemos analizar. El Art. 16 de la ley en comento establece que para efectos del saneamiento de la nulidad derivada de vicios formales que afecten la constitución, modificación, transformación, división, fusión, terminación o disolución de las personas jurídicas acogidas a esta ley, el titular o quien corresponda en derecho, deberá corregir el formulario en que conste el vicio. Agrega que "el procedimiento señalado sustituye a aquel establecido en la ley 19.499 en todo lo que sea contrario a la presente ley, respecto de las personas jurídicas regidas por esta". Este último precepto indica que esta ley solo varía la forma de corregir el vicio, esto es, artículos $3^{\circ}$ y $4^{\circ}$ de la ley 19.499, pero en todos lo restante se mantendría vigente esta última (Ej. plazo de prescripción). De este modo, si el llenado de este formulario contiene vicios de fondo que implican la privación de algún elemento esencial al concepto de sociedad o de general aplicación a los contratos, no podría ser saneado de acuerdo a este procedimiento.

Por su parte, el Art. 21 del Reglamento, dispone que los vicios formales que afecten la validez de una actuación y aquellos errores que, sin afectar la aludida validez, puedan ser subsanados o rectificados, se sujetará a lo establecido en la ley 19.499. "El administrador no dará curso al saneamiento o rectificación solicitada si no cumplen con los requisitos legales aplicables". Asimismo, el Art. 23 del citado cuerpo normativo, alude a la solicitud de rectificación, para ello dispone que cualquiera de los titulares o representantes o apoderados podrá requerir, a través de la suscripción de una solicitud de rectificación en conformidad a los artículos 15 y siguientes, subsanar o corregir los errores formales u omisiones manifiestas, siempre que dichos vicios tengan la calidad de rectificables de acuerdo a lo expresado en el art. 21. El administrador tendrá la facultad de realizar de oficio la rectificación de un error que cumpla con las características de dicha disposición. Realizada la rectificación, el Administrador enviará un correo electrónico a cada uno de los titulares de la persona jurídica de que se trate dando cuenta de la rectificación.

De la mano de ello, es claro que el Administrador del Registro ocupará un rol relevante en esta materia tanto para verificar los vicios, como en acoger la eventual solicitud y rectificar los vicios o errores. En esta 
línea, también debemos considerar que es el Estado quien propicia y administra este sistema, de manera que debiéramos preguntarnos hasta qué punto se le podría considerar a este como responsable de los actos efectuados por sociedades nulas, máxime si consideramos que no existe una supervisión de las constituciones, modificaciones, disolución o migraciones efectuadas.

Una inquietud que surge de los preceptos enunciados es qué ocurrirá con los actos realizados por la sociedad nula mientras ellos no sean saneados o rectificados. En este caso, pensamos que debieran aplicarse las normas generales sobre la materia que tienden a la protección de los terceros que han actuado de buena fe.

Otra norma que se aparta de la ley 19.499, es el Art. 22 inciso final del Reglamento, al expresar que la falta de suscripción del formulario dentro del plazo de 60 días desde la firma del primer titular, no se considerará un vicio formal de nulidad, sino que producirá la caducidad del formulario no suscrito. Con ello, el formulario que se inició pero no se concluyó en tiempo no debiera producir ningún efecto legal.

7. La suscripción del formulario electrónico debe incorporar la firma electrónica avanzada de los contribuyentes, socios o accionistas, según corresponda, si carecen de firma electrónica avanzada, podrán utilizar la firma de un notario público (Art. 9 Ley 20.659). En este caso, el notario deberá estampar su firma electrónica avanzada en el formulario de que se trate entendiéndose, de esta forma, suscrito el formulario por parte del constituyente, socios o accionista para todos los efectos.

El Art. 19 del Reglamento dispone el procedimiento para la suscripción mediante firma electrónica avanzada ante un notario en los casos señalados en el precepto anterior. Se señala que el Ministro de fe deberá descargar e imprimir el formulario o requerimiento de anotación que se pretende incorporar en el registro, este verificará la identidad del firmante y luego el notario firmará el documento impreso, para luego proceder a firmar el formulario mediante firma electrónica avanzada dentro del mismo día en que hubiere sido suscrito por los titulares. Surge de lo anterior la inquietud de saber cuál es el valor de este acto jurídico, una posibilidad sería considerar que se trata de un mandato legal.

Por otra parte, el documento impreso y firmado manualmente no juega ningún papel en este régimen simplificado, por lo que no se aprecia la finalidad de su establecimiento. En la práctica este papel firmado manualmente por los interesados queda en poder del Notario para acreditar la solicitud de las personas, pero no podrá registrarse, pues la ley nada prevé a este respeto.

8. La creación del Registro de sociedades es un aspecto que debe destacarse pues Chile estaba carente del mismo, e implica la consagración 
del principio de publicidad y libre acceso a las bases de datos de los formularios tipo para personas jurídicas reguladas en la ley. Sin embargo, al coexistir este sistema con el antiguo se llega a la conclusión que el registro arrojará una visión sesgada, pues solo estarán disponibles en línea las sociedades suscritas por medio de este sistema. A ello debe agregarse que no existe aún convicción sobre la seguridad de los registros computacionales, especialmente, que no puedan ser adulterados (o al menos, que su seguridad no sea inferior a las de los registros actuales) ${ }^{34}$.

Habría resultado interesante buscar un mecanismo que obligase a los notarios o Registros de Comercio a enviar los extractos de escrituras públicas o inscripciones a este nuevo Registro nacional con el objeto de contar con un instrumento unificado que nos permitiese visualizar estos datos de manera consistente y, desde allí, estudiar dichas realidades. Por otra parte, habría sido muy recomendable aspirar a un sistema de registro que resguarde la fe pública revisando la legalidad de los instrumentos que allí se inscriben, tanto en su formato electrónico, como tradicional. La ausencia de ello nos obliga a cuestionarnos seriamente por la necesidad de su existencia.

En cuanto al hecho que el registro rige en todo el territorio de la República, cabe preguntarse por su real significado. En nuestra opinión, esto implica algo evidente como es la consideración que el registro no es regional o comunal, como ocurre con los Registros de comercio, y también que las sociedades suscritas bajo este sistema se considerarán nacionales para la aplicación de la lex societatis, con independencia del lugar en que se han realizado (podrían suscribirse desde fuera del país).

9. La ley 20.659 proclama la gratuidad de este sistema sin introducir parámetros, a diferencia de otras normas similares (Ej. 20.494). Ello nos permite reflexionar y cuestionar la necesidad de brindar gratuidad a sociedades que se constituyen con montos elevados o disponen de recursos económicos suficientes. En otras palabras, ¿es necesario que el Estado subsidie a quienes disponen de recursos económicos? ¿No habría sido mejor subsidiar a los pequeńos empresarios con objetos realmente productivos? La implementación de este sistema tiene un costo y este debe ser asumido por todos los contribuyentes, de manera que si bien es gratuito para las empresas, es costoso para todos nosotros. El fundamento parece inexistente.

34 González, Natalia; Monsalves, Daniel, Nuevo régimen de constitución simplificada de sociedades comerciales, Fundación Libertad y Desarrollo, Serie de Informe legislativo, $\mathrm{N}^{\circ} 35$, disponible en http://www.lyd.com/wp-content/files_mf/sil35nuevoregimendeconstitucionsimplificadadesociedades comercialesngonzalezydmontalvamayo2013.pdf (visitado el 10 de agosto de 2013), p. 29. 
10. Otra pregunta relevante dice relación con el resguardo a la autonomía de la voluntad: ¿Hasta qué punto el formulario establecido permite a los socios plasmar su auténtica voluntad? Esta es una inquietud relevante si consideramos que el Derecho societario se basa principalmente en la autonomía de la voluntad, la que puede verse trastocada si las sociedades se constituyen solo llenado formularios. Ligado a ello, podemos preguntarnos si es posible hablar de un "contrato de sociedad", de la forma en que está concebido el Art. 2053 del CC, lo que nos invita a revisar esta clásica configuración.

11. En relación al aporte de los socios, si quienes están constituyendo esta sociedad simplificada, señalan en el formulario que su aporte es en un inmueble por ejemplo, el sistema no exige individualización alguna de él, ni dirección, medidas, deslindes, o inscripción en el Registro de Propiedad del Conservador respectivo. El Reglamento de la ley 20.659, en su Art.10, establece en relación a ese aporte la necesidad de cumplir las formalidades o solemnidades especiales para enterar el aporte, según el tipo de bien. Agrega el inciso $2^{\circ}$ que mientras no se dé cumplimiento a esas solemnidades, las estipulaciones, pactos o acuerdos no producen efecto alguno. Algo similar, pero menos claro, establece la ley, toda vez que en su Art. $8^{\circ}$ esta dispone que "cuando se requiera de formalidades o solemnidades especiales para enterar el aporte, según el tipo de bien, deberá efectuarse conforme a ellas. Mientras no se dé cumplimiento a lo señalado en el inciso anterior, las estipulaciones, pactos o acuerdos que establezcan los interesados no producirán efecto, sin perjuicio de las demás sanciones que a este respecto dispongan las leyes que establecen y regulan a las respectivas personas jurídicas". La diferencia, claro está, se encuentra en que mientras este último precepto indica que no producirá efecto "frente a terceros", el Reglamento amplía lo anterior señalando que no producen efecto, lo que resulta acertado considerando lo dispuesto en los artículos 2053 y 2055 del CC.

A partir de lo anterior, la sociedad no se podrá constituir en un día como se pretendía, pues a diferencia del sistema tradicional -en que solo se precisa una escritura- en este caso, las partes o socios deberán suscribir obligadamente un segundo acto jurídico, como una escritura pública u otra formalidad adicional, dependiendo del tipo de bien (Ej. Bienes raíces, vehículos motorizados, acciones de sociedades anónimas, marcas comerciales, entre otros) con el objeto de concurrir al aporte de la sociedad. En tal sentido, el instrumento constitutivo de este sistema no se basta a sí mismo en todos los casos, lo que puede verse como una debilidad del sistema. Quizás en estos casos convenga la realización de la sociedad bajo el sistema tradicional con el objeto de evitar complicaciones en este punto, lo que dejaría sentado el hecho que el nuevo sistema no se ajusta a todas las necesidades del Derecho societario. 
Adicionalmente, debemos subrayar el hecho que no se confiere un plazo para estos efectos de manera que es posible que una sociedad quede inconclusa, y más grave aún, que el sistema tampoco detecta este tipo de aportes, por lo que las partes podrían entender que han constituido válidamente la sociedad.

12. En el mismo sentido debemos reparar en el hecho que el artículo 10 de la ley 20.659 dispone un plazo de 60 días contados desde la firma del primero de ellos, para que el resto de los socios concurra a suscribir el contrato. Este plazo parece excesivamente largo si consideramos las finalidades previstas en la ley, que pretendía la celeridad de la constitución y otras materias, y finalmente termina confiriendo un plazo similar al que tienen las sociedades constituidas en el sistema tradicional para completar su tramitación. Lamentablemente parece no haber sido un punto reparado en la tramitación legislativa correspondiente, según se desprende de la historia de aquella.

13. El formulario disponible en internet puede ser completado por cualquier persona, independiente si tiene o no conocimientos en la materia, y por el solo hecho de su llenado el sistema lo publica de forma inmediata en el Registro de Empresas y Sociedades, lo que conlleva como consecuencia que el SII deba asignar un RUT a una empresa que no sabemos si es válida, ya que no hay una supervisión por parte de un entendido en Derecho. La participación del notario es solo en casos en que los socios o accionistas no tengan firma electrónica avanzada, y su labor no es revisar la redacción del documento. Esto, si bien facilita el emprendimiento, también puede establecer un manto de dudas o inseguridades a nivel comercial.

14. En relación a las migraciones, considero que la normativa contiene una inconsistencia en relación a las migraciones de las personas jurídicas que se hayan acogido a esta ley y que con posterioridad dejen de corresponder a algunas de las indicadas en el artículo $2^{\circ}$, pues para ello impone que sean los titulares de los derechos sociales o acciones de la sociedad los que suscriban el formulario denominado "de migración al régimen general" (Art. 19).

La suscripción de dicho formulario deberá efectuarse conforme a las normas establecidas en el Título III de esta ley. Si nada dijeren el contrato social o los estatutos, la migración deberá aprobarse por la totalidad de los titulares de los derechos sociales, y en el caso de sociedades cuyos acuerdos deban adoptarse por juntas, por mayoría absoluta de las acciones emitidas con derecho a voto. El acta que se levante de la junta, previo cumplimiento de las formalidades que sean necesarias, deberá ser reducida a escritura pública o protocolizada, según corresponda. 
La pregunta que surge es qué ocurrirá con las sociedades que se encuentran en esta situación y no realizan este trámite. No se trata de un acto automático o donde se faculte a la entidad administradora para fiscalizar o realizar, por lo que podría ocurrir que -frente a la inobservancia- la ley termine siendo aplicable a sociedades que no forman parte de su ámbito de aplicación (Art. $2^{\circ}$ ), y ello carezca de toda sanción, pues la normativa no la contempla.

15. Finalmente, en relación a las fusiones y divisiones, vemos acentuada la disparidad en que se encontrarán las sociedades regidas por los regímenes coexistentes. En efecto, la ley en comento señala que "En los casos de fusión de personas juridicas acogidas a la presente ley con personas juridicas que no lo están, cada una de ellas deberá cumplir con las solemnidades que particularmente le son aplicables para efectos de celebrar la fusión y la persona juridica resultante de esta continuará regulada por el régimen de formalidades que le resulte aplicable, sin perjuicio que posteriormente migre a otro régimen. En el caso de división de una persona juridica a la cual se le aplica la presente ley, la nueva persona juridica que se constituya al efecto deberá acogerse a las disposiciones de esta ley, sin perjuicio de que posteriormente migre a otro régimen" (Art. 15).

Por otra parte, el reglamento contiene menciones dispersas frente a la fusión y todo parece indicar que se trata de una regulación incompleta, de manera tal que habrá de tenerse especial precaución para evitar conflictos futuros.

\section{Algunas CONCLUSIONES}

Las leyes analizadas han simplificado la constitución de sociedades, alivianando la carga económica y temporal para los socios y accionistas, todo en aras de facilitar el emprendimiento nacional, mejorar del entorno de negocios de las empresas y lograr una mayor competitividad del país.

En mi consideración, si bien estas leyes buscan la simplificación del Derecho societario, y de cierta medida lo logran, me parece que faltó en su discusión mayores estudios dogmático-jurídicos que ilustrasen sobre la conveniencia de tomar ciertas medidas. En tal sentido, si lo que se pretendía era lograr una mayor eficiencia en el uso de los tiempos, podría haberse instruido a los Notarios, una vez revisado el contenido, enviar las escrituras a un registro nacional unificado, creado para estos efectos, junto con disponer dicha información al SII, o bien haber establecido canales de fiscalización antes de hacer factible la constitución societaria. La disparidad existente entre ambos sistemas no parece en modo alguno algo inocua.

El régimen simplificado establecido en la ley 20.659 deberá irse perfeccionando con la puesta en práctica y con la experiencia que adquiera 
el administrador del Registro de Empresas y Sociedades, los tribunales de justicia y demás organismos llamados a aplicarlo, es recomendable que se efectúen ciertos ajustes. Un proceso similar de implementación, adaptación y perfeccionamiento se requerirá a nivel de los principales agentes del mercado (emprendedores, inversionistas, abogados, bancos, entidades públicas). Junto con las medidas legislativas de ajuste, habrá que hacer lo propio con la implementación de este sistema computacional, y con la necesaria educación que debe entregarse a los emprendedores en dicho sentido.

Finalmente, considero que si bien estas leyes contribuyen en la modernización del Derecho societario, ello solo se refleja en la simplificación de trámites, echo de menos una revisión legislativa más profunda que tienda a la modernización desde una perspectiva jurídica y no solo económica, que valore los cambios introducidos en esta materia en Derecho comparado.

\section{BIBLIOGRAFÍA}

- Boletines Empresas (mayo y junio) en un día publicado en: http:// www.economia.gob.cl/constitucion-de-empresas-en-1-dia/ [visitado el 18/08/2013].

- Doing Business. Banco Mundial IFC 2012 Haciendo negocios en un mundo más transparente. Comparación de la Regulación. En: http:// espanol.dolingbusiness.org/media/FPDKM/Doing\%20Foreign/ DB12-Business/Documents/Annual-Reports/Spanish.pdf. [visitado el 14/7/2013].

- García Tabuenca, Antonio; Crespo, José luis; Sanz Tringuero, María (2010), "El coste económico en la creación de sociedades", en Hierro Anibarro, Santiago (Director), Simplificar el Derecho de Sociedades, Madrid, Marcial Pons.

- González, Natalia; Monsalves, Daniel, Nuevo régimen de constitución simplificada de sociedades comerciales, Fundación Libertad y Desarrollo, Serie de Informe legislativo, $\mathrm{N}^{\circ} 35$, disponible en http://www.lyd.com/wp-content/files_mf/ sil35nuevoregimendeconstitucionsimplificadadesociedades comercialesngonzalezydmontalvamayo2013.pdf (visitado el 10 de agosto de 2013), p. 29.

- Hierro Anibarro, Santiago, (2010), "Una introducción a la simplificación del Derecho de sociedades", en Hierro Anibarro, Santiago (Director), Simplificar el Derecho de Sociedades, Madrid, Marcial Pons

- Hopt, K. J. (2007), "Corporate Governance: Vergleichende privatrechtliche Forstchung im Aktien - und Kapitalmarktrecht", en Gesellschaft, Jahresbericht der Max- Planck 
- Puelma Accorsi, A. (2001) Sociedades. Santiago, Ed. Jurídica de Chile.

- Vásquez Palma, Fernanda M. (2013), Sociedades. Comerciantes, empresas, grupos de empresas y otros sujetos del Derecho Comercial, Santiago de Chile, Ed. LegalPublishing-Thomson Reuters. 